\title{
Diversidad cultural y acomodos razonables. Una lectura desde la no dominación
}

\author{
Isabel WeNCES* \\ Universidad Carlos III de Madrid \\ iwences@polsoc.uc3m.es
}

Recibido: 3 de julio de 2014

Aceptado: 18 de agosto de 2014

\section{RESUMEN}

Entre los retos que afrontan las actuales sociedades culturalmente diversas se encuentra el de aprender a convivir en la diferencia. Uno de los mecanismos que se ensaya en los procesos de gestión de la diversidad cultural es el de las prácticas de armonización, entre las que se encuentran los ajustes concertados y los acomodos razonables. Estos últimos se justifican sobre la base del reconocimiento de la igualdad en la diferencia, pero también se pueden fundamentar en una idea de libertad como no dominación que atienda la desigualdad en las relaciones de poder.

\section{PALABRAS CLAVE}

Diversidad cultural, acomodos razonables, libertad como no dominación, interculturalismo, republicanismo.

\section{Cultural Diversity and Reasonable Accommodation. An Approach based on Freedom as Non-domination}

\begin{abstract}
One of the challenges that culturally diverse societies now face is that of learning to live with differences. Harmonization practices such as concerted adjustment and reasonable accommodation are some of the mechanisms proposed by cultural diversity management policies to deal with this contemporary situation. In the case of reasonable accommodation, this practice can be justified not only because it is based on a recognition of equality in difference, but also on a belief in freedom as a form of nondomination, given the inequality present in power relations.
\end{abstract}

* Agradezco a Alain-G. Gagnon, Director de la Chaire de recherche du Canada en études québécoises et canadiennes (CREQC) de la Université du Québec à Montréal, la generosidad y sugerencias que ha tenido conmigo y mi trabajo. El presente artículo se enmarca en el Proyecto de Investigación $\mathrm{I}+\mathrm{D}+\mathrm{i}$ : "Identidades y ciudadanías. Fundamentos político jurídicos de la diversidad", financiado por el Ministerio de Economía y Competitividad en el marco del Plan Nacional I+D, número de expediente DER2012-36142. Asimismo, agradezco a los evaluadores las sugerencias realizadas para mejorar este trabajo. 


\section{KEY WORDS}

Cultural diversity, reasonable accommodation, freedom as non-domination, interculturalism, republicanism.

\section{INTRODUCCIÓN}

El fin último que motiva estas páginas es aportar ideas que ayuden a encontrar respuestas a la gran pregunta que Michel Wieviorka planteara en términos de teoría política: ¿cómo vivir juntos con nuestras diferencias? ¿Sobre la base de qué principios de justicia, de qué concepción de la igualdad y de qué concepción de la libertad?‥ La necesidad de articular la convivencia en sociedades pluriculturales requiere de reflexiones y compromisos que, en un marco de pluralismo interactivo e integrador, se aleje del relativismo, los procesos atomizadores y del monoculturalismo uniformador. El presente trabajo se mueve en el marco de un modelo de diversidad cultural específico, el de un interculturalismo cuyos fundamentos son la convivencia y la interacción basados en una dinámica de interacciones e intercambios, de no discriminación, de respeto a la diferencia y de reciprocidad. Este interculturalismo considera esenciales las prácticas ciudadanas de armonización intercultural y, dentro de ellas, prioriza los ajustes concertados y admite como vía para evitar la discriminación a los acomodos razonables. Estos últimos, no exentos de críticas, encuentran diversas fundamentaciones. Aquí se propone justificar su alcance como un camino más para evitar la dominación en sociedades culturalmente diversas que pretenden fomentar el diálogo y la armonía mediante equilibrios entre mayorías y minorías. El acento está puesto en las relaciones de poder más que en las cuestiones identitarias. La libertad como no dominación es una apuesta por una determinada manera de entender el republicanismo, el cual puede entablar vías de encuentro con el interculturalismo, siempre y cuando se aleje de la perspectiva comunitarista y asimilacionista y sea pluralista e inclusivo.

Antes de continuar conviene subrayar que "Diversidad cultural y acomodos razonables. Una lectura desde la no dominación" es un artículo que se enmarca en el ámbito de una teoría política que se entiende normativa, filosófica y práctica, dado que las dos primeras dimensiones ven sus principios reflejados en diseños institucionales. Con base en estos parámetros, dos cuestiones se encuentran en los cimientos de estas páginas. En primer lugar, que las propuestas nor-

${ }^{1}$ Michel Wieviorka, La Diversité. Rapport à la ministre de l'Enseignement supérieur et de la Recherche, Robert Laffont, Paris, 2008. 
mativas tienen que orientar sus principios de tal manera que puedan actuar sobre la realidad, modificándola y mejorándola; no basta con que se interprete y comprenda la complejidad que supone la diversidad cultural y se atienda desde el pluralismo. Es imprescindible que se reflexione "sobre aquello que podría ayudar a transformarla" porque como bien subrayara Rafael del Águila "la vocación de la Teoría Política no es (en realidad nunca fue) vivir al margen del mundo, sino intervenir en él"’. En segundo lugar, para llevar a cabo este objetivo, hay que tener claro que al gestionar las diferencias culturales que tienen lugar en un mismo espacio se requiere adoptar medidas de acomodo de la diversidad, asentar las condiciones para la inclusión de derechos y hacer adecuaciones institucionales. Por tanto, es vital considerar el elemento contextual, esto es, el escenario social, político y jurídico en el que se está inmerso.

Teniendo en cuenta esta perspectiva, el presente trabajo se articula en torno a tres apartados. En el primero se aclara cuál es el tipo de republicanismo que da soporte a la idea de libertad como no dominación, desde la cual se pretende hacer una lectura de los acomodos razonables, y se explica en qué consiste el interculturalismo en cuanto andamio a partir del cual se construye una determinada manera de entender la gestión de la diversidad cultural. En segundo lugar, se argumenta por qué los acomodos razonables, en particular, y las prácticas de armonización intercultural, en general, pueden justificarse desde los parámetros de la no dominación. Y, en tercer lugar, se enlaza el discurso de la no dominación con dos cuestiones claves de la gestión intercultural de la diversidad cultural que son: ¿quién decide y cómo se decide qué prácticas culturales merecen reconocimiento?

\section{Libertad como no dominación e interculturalismo. Precisiones con- CEPTUALES}

La libertad como no dominación es un principio enarbolado por el republicanismo, una tradición de pensamiento político de largo recorrido con proyección en contextos políticos y sociales diversos y que ha dado lugar a múltiples interpretaciones. Dentro de los posibles modelos de republicanismo el que aquí me interesa recuperar es el republicanismo pluralista, desde el punto de vista cultural, y

\footnotetext{
${ }^{2}$ Alain Renaut, “¿Qu'est-ce qu'une philosophie politique juste? Essai de philosophie politique appliquée”: Politique et Sociétés, vol. 22, n. 3 (2003), p. 156.

${ }^{3}$ Rafael Del ÁGUILA "Introducción al Monográfico especial sobre la teoría política contemporánea”: Revista Española de Ciencia Política, n. 3 (2000), p. 8.
} 
democrático, desde la perspectiva política. Estos dos ejes, cultural y político, configuran distintas modalidades de republicanismo. De acuerdo con Andrés de Francisco, en relación al eje cultural, el republicanismo discurre desde un extremo pluralista a uno comunitarista; el eje político sitúa en un extremo la oligarquía y en el otro la democracia. En el polo oligárquico la ciudadanía es cívicamente débil, mientras que en el polo democrático esta se presenta robusta y fuerte. De Francisco cruza estos dos ejes y obtiene las siguientes modalidades: republicanismo oligárquico pluralista, republicanismo oligárquico comunitarista, republicanismo democrático-comunitarista y republicanismo democrático pluralista $^{4}$. Este último, acompañado de algunos matices que subrayaré más adelante, es el que desde mi perspectiva puede entablar un diálogo fructífero con el interculturalismo, con quien hallará especiales puntos de convergencia como el justificar los acomodos razonables desde la no dominación en situaciones de discriminación indirecta, sin que ello signifique la ausencia, en otros aspectos, de considerables divergencias.

El republicanismo pluralista, o crítico como le denominan algunos autores ${ }^{5}$, se siente "cómodo en sociedades culturalmente abiertas"; se muestra comprensivo con la diversidad de concepciones del bien y de la buena vida, y acepta sin temor la diferencia y el disenso, lo que lo convierte en inclusivo. Un dato a tener en cuenta es que al hablar de diversidad no necesariamente se está haciendo referencia al pluralismo. Desde una perspectiva histórica, el concepto de pluralismo tiene un largo recorrido que va de las primeras manifestaciones de tolerancia a una tolerancia que respeta el desacuerdo "y finalmente, a través del respeto, a la

${ }^{4}$ En cuanto democrático, afirma De Francisco, aspira a incluir en la plena ciudadanía a los menos apoderados y más vulnerables a fin de que sean libres; en cuanto pluralista, aspira a "incorporar al espacio público de la deliberación política el mayor número de concepciones de la buena sociedad y a encajar las distintas formas de vida privada en un marco razonablemente bien integrado de convivencia social". Andrés De Francisco, La mirada republicana, Catarata, Madrid, 2012, p. 48.

${ }^{5}$ El republicanismo crítico consiste en la articulación de dos perspectivas, la socialdemócrata y la inclusiva. Este modelo defiende una sociedad en la que todos los ciudadanos puedan gozar de un estatus legal que implique un igual derecho a la palabra, a la autonomía personal, a oportunidades vitales, al reconocimiento mutuo y a una solidaridad interétnica. En su defensa de una igualdad social este republicanismo crítico pone sobre la mesa la constatación de que las desigualdades económicas y la exclusión social exacerban las diferencias étnicas y culturales. Cécile Laborde, Critical Republicanism. The Hijab Controversy and Political Philosophy, Oxford University Press, Oxford, 2008, p. 11. 
creencia en la fecundidad del antagonismo en la medida en que es una de las condiciones de la autonomía individual".

Además de pluralista, este republicanismo se aleja del asimilacionismo y de la visión particularista, excluyente y homogénea más propia del comunitarismo radical y, en cambio, abre sus puertas a la diversidad en un marco de no dominación. Por el contrario, el republicanismo comunitarista es estático y se inclina claramente por una "república más homogénea, culturalmente cerrada y autorreferencial" ". El republicanismo pluralista e inclusivo comparte con su familia republicana la apuesta por la igualdad política, la deliberación pública, la necesidad de la virtud, el combate de la corrupción y la reivindicación de la política, pero a diferencia de otras versiones de esa misma familia reconoce que la diversidad es una dimensión intrínseca de nuestras sociedades, es dinámico y no muestra resistencia al cambio cultural; en consecuencia, cuestiona el modelo de república indivisible y de uniformidad endémica. Con este planteamiento, al referirme al republicanismo me alejo de la visión monista y hegemónica que favorece a una mayoría cultural a través de la asimilación ${ }^{8}$ y que considera que la pertenencia a una comunidad de valores, sean culturales o nacionales, es un bien intrínseco; como sucede en el modelo francés que "bajo la brillante superficie del universalismo republicano de los derechos" hace operar "en la sombra el particularismo nacionalista del asimilacionismo cultural" .

Por interculturalismo se va a entender, tanto en su condición de proyecto político como de presupuesto teórico, un modelo de diversidad cultural fundamentado en el ideal del pluralismo y de la integración, donde la práctica de interacciones, el rechazo a toda discriminación y la promoción de una cultura pública común son factores esenciales. Es oportuno, a fin de evitar confusiones e interpretaciones erróneas, aclarar algunos de los conceptos clave que hemos

6 "De l'intolérance à la tolérance, de la tolérance au respect du désaccord et enfin, par l'entremise de ce respect, à la croyance en la fécondité de l'antagonisme en tant qu'il est une des conditions de l'autonomie individuelle". Justine LaCroIX, "Communautarisme et pluralisme dans le débat français. Essai d'élucidation": Éthique Publique, vol. 9, n. ${ }^{\circ} 1$ (2007), p. 53.

${ }^{7}$ DE FRANCISCO, La mirada republicana, p. 46.

${ }^{8}$ Críticas a este modelo se encuentran en Dimitris Karmis, "Pluralismo e identidad(es) nacional(es) en el Quebec contemporáneo: aclaraciones conceptuales, tipología y análisis del discurso", en Alain-G. GAGNON (comp.), Quebec: Estado y Sociedad, Universidad de Guadalajara, Guadalajara (México), 2003.

${ }^{9}$ Ramón MÁIz, "Nacionalismo e inmigración en Francia: La republique une et indivisible y el affaire du foulard": Revista de Estudios Politicos (nueva época), n. ${ }^{\circ} 129$ (2005), p. 25. Sobre este modelo monista que practica la exclusión véase: Pierre RosAnvallon, Le sacre du citoyen, Gallimard, Paris, 1992. 
mencionado. Cuando se habla de pluralismo se está aludiendo a esa familia de doctrinas que defienden una ciudadanía inclusiva e igualitaria, así como "plural y diferenciada en sus dimensiones tanto legales como psicológicas y políticas" y que, en consecuencia, rechaza los modelos monistas, exclusivos y discriminatorios $^{10}$. Por otro lado, la integración que aquí me interesa tiene una dimensión incluyente, por lo que su proceso no debe confundirse con proveer al conjunto de los ciudadanos de una comunidad de idénticos puntos de referencia, lo que se calificaría de excluyente. En cambio, apuesta por una lógica en la que las minorías no se sientan amenazadas, sino parte de un proyecto que pretende promover la edificación de una identidad con componentes amplios y flexibles que se abra a toda la diversidad etnocultural "mediante intercambios e interacciones" de ciudadanos de todos los orígenes que buscan a la vez nutrirse de la comunidad de origen y contribuir a un proyecto de construcción común que fomente el desarrollo de un sentimiento de pertenencia ${ }^{11}$. Esto significa que debe tenerse cuidado con la defensa de una supuesta neutralidad estatal que la mayoría de las veces oculta, bajo el paraguas de una serie de políticas, la hegemonía del grupo mayoritario $^{12}$, pero también con llevar al extremo la protección de minorías ${ }^{13}$.

El interculturalismo, así entendido, posee algunas características que lo diferencian de otros modelos también pluralistas, entre ellos del multiculturalismo. De la mano de Dimitrios Karmis podemos subrayar tres. Por una parte, para este modelo, el pluralismo no se limita a las comunidades y naciones etnoculturales, sino que también toma en consideración estilos de vida y concepciones del mundo. Por otra parte, las comunidades culturales no están yuxtapuestas, sino

${ }^{10}$ KARMIS, "Pluralismo e identidad(es) nacional(es) en el Quebec contemporáneo: aclaraciones conceptuales, tipología y análisis del discurso", pp. 82-83.

${ }^{11}$ Gérard Bouchard y Charles TAYLOR, Fonder l'avenir. Le temps de la conciliation, Gouvernement du Québec, Québec, 2008, p. 128. Conviene subrayar que el término integración puede dar lugar a confusiones y que algunos autores lo asocian a políticas de asimilación y subordinación, pero en estas páginas la integración alude a un proceso de interacción y reciprocidad.

${ }^{12}$ Un trabajo extraordinario que muestra con claridad esta situación es el de Cécile Laborde quien denuncia que en el escenario francés las instituciones mayoritarias no son ni plenamente republicanas ni laicas, sino todo lo contrario, "se encuentran colmadas de residuos de la religión históricamente dominante, el catolicismo". El republicanismo oficial, dicho brevemente, ve las mezquitas, pero ignora las iglesias, se "centra exclusivamente sobre cómo las cosas deberían ser y no pone ninguna atención a justificar o criticar cómo son...el Estado francés no es ni indiferente de cara a las religiones, ni tampoco neutro". LABORDE, Critical Republicanism. The Hijab Controversy and Political Philosophy, p. 82.

${ }^{13} \mathrm{Si}$ el tema de la "dictadura de las minorías" ocupó en las últimas décadas una gran atención de académicos y políticos, hoy en día se ha puesto sobre la mesa la "afirmación de las mayorías" quienes reclaman que nos ocupemos de ellas, de su identidad, del lugar que ocupan en las actuales sociedades complejas. Véase: Jean-François LiséE, Nous, Boréal, Montréal, 2007. 
entremezcladas. Y, finalmente, reconoce que los individuos cuentan con múltiples identidades y que ninguna de ellas debiera ser lo suficientemente dominante como para subordinar a las otras ${ }^{14}$.

Diversos integrantes de la Escuela Canadiense de la Diversidad han dedicado notables esfuerzos a dar cuerpo a una determinada manera de vislumbrar al interculturalismo y es en sus presupuestos normativos y en sus guías para la acción política que dirigimos la atención ${ }^{15}$. Para pensadores como Gérard Bouchard y Charles Taylor, el interculturalismo, además de proteger los derechos y las libertades individuales, promover valores comunes y defender la igualdad entre hombres y mujeres en un contexto siempre democrático, es un modelo en el que los ciudadanos venidos de fuera (inmigrantes) y los miembros de diversos grupos minoritarios de origen canadiense (anglófonos, inuit, miembros de las primeras naciones, primeros colonos, comunidades culturales autóctonas o minorías religiosas asentadas hace bastante tiempo como los judíos ortodoxos), si así lo desean, preservan lo esencial o una parte substancial de su cultura y la conjugan con componentes de la cultura mayoritaria. A sus valores fundamentales y costumbres agregan la lengua francesa, que es la lengua oficial pública, y en conjunto participan de la cultura pública común. A cambio, el grupo mayoritario también incorpora valores de culturas minoritarias. De esta manera, se encuentran los dos polos que dan cuerpo al interculturalismo: interacción y diversidad. En la medida en que va dándose este proceso, la diferencia cultural sobrevive mediante una dinámica de interacción respetuosa del otro y el reconocimiento de la diversidad como un hecho positivo, lo que constituye un equilibrio, siempre dinámico, entre convivencia, interacción, inclusión, diversidad y cohesión social ${ }^{16}$. Como consecuencia de la interacción entre los distintos grupos culturales se asume que el conjunto se irá transformando.

${ }^{14}$ KARMIS, "Pluralismo e identidad(es) nacional(es) en el Quebec contemporáneo: aclaraciones conceptuales, tipología y análisis del discurso", p. 93.

${ }^{15} \mathrm{Si}$ bien en este trabajo me centraré en el modelo de interculturalismo propuesto por la Escuela Canadiense de la Diversidad, especialmente en las propuestas elaboradas por académico de Universidades de Quebec y de Ottawa, no se ignora que América Latina y Europa se han unido a la reflexión de sus presupuestos como consta, entre otros muchos trabajos, en la creciente literatura latinoamericana dedicada al tema y en la publicación en 2009 por parte del Consejo de Europa del Libro Blanco sobre el Diálogo Intercultural: "Vivir juntos con igual dignidad". Disponible en: http://www.coe.int/t/dg4/intercultural/Source/Pub_White_Paper/WhitePaper_ID_SpanishVersion.pdf (13/02/2014).

${ }^{16}$ Gérard Bouchard y Charles TAYLOR, Accommodements et différences. Vers un terrain d'entente: la parole aux citoyens, Gouvernement du Québec, Québec, 2007, p. 21. 


\section{LA LIBERTAD COMO NO DOMINACIÓN Y LOS ACOMODOS RAZONABLES}

La libertad política de los ciudadanos es un tema que ha acaparado a lo largo ya de varios siglos la atención de los filósofos políticos. En las últimas décadas, numerosos teóricos de estirpe republicana han coincidido - a pesar de sus diferencias en otros ámbitos- en la importancia de apostar por una libertad que implique el rechazo de toda forma de servidumbre y control y que abogue no solo por la no interferencia, sino también por la no dominación. Desde esta perspectiva, la libertad consiste en que los hombres no se sientan amenazados por posibles obstáculos, imposiciones o sometimientos de otros, esto es, que no se encuentren en una situación de dominio por parte de una voluntad arbitraria. La "libertad como no dominación exige que nadie sea capaz de interferir arbitrariamente — según le plazca - en las elecciones de la persona libre"17. Siguiendo esta lógica, lo contrario a la libertad no es, como algunos consideran, la coerción, sino la dominación. "Ser libre, pues, no es una circunstancia (no verse forzado a hacer o dejar de hacer algo) sino una condición estructural: uno deja de ser libre tan pronto como se encuentra en una posición que lo hace susceptible de verse sometido a la voluntad de otro"18. De acuerdo con Philip Pettit, la libertad como no dominación es un tipo de libertad que se tiene en tanto que nadie controla con o sin interferencia- el ejercicio de las elecciones individuales y es una propiedad que solo puede concretarse si, a su vez, se asegura la igualdad en su disfrute. Pettit lo explica en estos términos:

Al proteger al más débil amplía sus posibilidades de no dominación sin reducir o perjudicar a los demás. Pero si solo protege al más fuerte devendrá ineficaz por dos razones. En primer lugar, porque el incremento de protección no acarreará el aumento de los niveles de no dominación del más débil. Es decir, garantizaría doblemente al más seguro. Y, en segundo lugar, porque el incremento de protección al más fuerte equivale a facilitarle un nuevo recurso para imponerse al más débil y reducir sus posibilidades de no dominación ${ }^{19}$.

El republicanismo, o neo-republicanismo, que ofrece el armazón sobre el que se sostiene la libertad como no dominación, aboga por una concepción inclu-

\footnotetext{
${ }^{17}$ Philip Petrit, Republicanismo. Una teoría sobre la libertad y el gobierno, Paidós, Barcelona, 1999, p. 349.

${ }^{18}$ Elías PALTI, "Ideas políticas e historia intelectual: Texto y contexto en la obra reciente de Quentin Skinner”: Prismas. Revista de historia intelectual, n. ${ }^{\circ} 3$ (1999), pp. 263-274.

${ }^{19}$ Philip Pettit, "De la República a la Democracia": Revista Internacional de Pensamiento Politico, vol. 4 (2009), p. 50.
} 
siva de todos los miembros que comparten una sociedad. La manera en que se mantiene la libertad como no dominación es a través, primero, de una serie de recursos diseñados por el Estado para supervisar cualquier intento de dominación que otros miembros o grupos de miembros intenten llevar a cabo; y, segundo, mediante el establecimiento de límites que regulen la propia interferencia del Estado, el cual debe estar sujeto a un control ciudadano efectivo. Esto no quiere decir que se legitime la intervención estatal en todos los ámbitos en nombre de la libertad. El papel del Estado no es el de constreñir a los individuos para que ejerzan su autonomía, sino el de darles los medios para que puedan ejercerla sin que sean dominados por otros. Cécile Laborde, en su defensa del republicanismo crítico, sostiene que en lugar de optar por inculcar directamente normas o acudir a la vía del castigo hay numerosos diseños institucionales que pueden evitar repercusiones provenientes de la dominación ejercida al amparo de ciertas normas sociales ${ }^{20}$.

Así, la doctrina política republicana defiende una compresión de la libertad como no dominación que significa una forma de protección más segura frente a las interferencias. Iseult Honohan explica con acierto esta idea cuando señala que no se trata estrictamente de desafiar los actos de interferencia, sino de combatir la condición de subordinación que hace que dichos actos sean posibles. Las implicaciones políticas de esta concepción de la libertad se reflejan en la exigencia de un conjunto de mecanismos e instituciones que proporcione garantías frente a las interferencias ilegítimas, de tal manera que los ciudadanos puedan actuar de manera independiente ${ }^{21}$. El propio Honohan señala que se requieren diversos e imaginativos diseños institucionales para asegurar esta libertad. La propuesta que aquí se ensaya es la de considerar las prácticas de armonización intercultural, tanto en su vertiente de ajuste concertado como de acomodo razonable, como uno de esos posibles diseños para evitar la dominación.

El punto de encuentro entre republicanismo e interculturalismo -entendidos como se ha señalado- no es la exigencia de que los ciudadanos deban ver sus identidades particulares reconocidas por el Estado; lo que cobra importancia es que no sean dependientes ni estén dominados, ni por los miembros de su propia comunidad ni por la sociedad mayoritaria. Esto exige, a su vez, que la igualdad sea interpretada más allá de su mera connotación formal.

El significado profundo de esta perspectiva en el hilo de nuestro discurso requiere una atención más detallada. Conviene empezar por distinguir entre las

\footnotetext{
${ }^{20}$ Cécile LABORDE, Français, encore, un effort pour être républicains, Seuil, Paris, 2010.

${ }^{21}$ Iseult Honohan, Civic Republicanism, Routledge, London y New York, 2002.
} 
normas jurídicas que comportan principios neutros y universales (por ejemplo, la igualdad entre los sexos), y las normas y reglas que reproducen valores y normas propias de la cultura mayoritaria (por ejemplo, determinada forma de vestir, especialmente en el caso de las mujeres, o las festividades religiosas permitidas e incluso fomentadas institucionalmente y que tienen lugar en la vía pública). En cuanto al primer principio, tanto el republicanismo como el interculturalismo concuerdan en que su disfrute no admite posibilidad alguna de excepción o de acomodo; mientras que el segundo presupuesto se acompaña de una fuerza normativa más endeble, dado que se encuentra sujeto a contextos culturales determinados. Esta preocupación en distinguir entre lo universal y lo particular, si bien ausente en diversas versiones de la tradición republicana, no es ignorada por el republicanismo pluralista e inclusivo. El acomodo razonable es compatible con un republicanismo que sabe que la esfera pública no es cultural y religiosamente homogénea y que considera necesario no solo aceptar su pluralidad sino, además, adoptar medidas para que esta se exprese. Es lógico pensar que ninguna persona pretenderá, por ejemplo, que sea razonable instaurar políticas neutras en relación al uso de la lengua en los servicios públicos, en los tribunales, en el Parlamento o en las escuelas. Una comunidad política no puede ser completamente neutra desde la perspectiva cultural, puesto que las normas de la vida pública tienen inevitablemente un origen histórico y emanan generalmente del grupo cultural mayoritario. Si la ley y las instituciones públicas no son neutras desde el punto de vista cultural y religioso ${ }^{22}$, ciertos acomodos razonables en favor de miembros de minorías que padecen algún tipo de discriminación pueden ser considerados demandas de no dominación y de restablecimiento de la igualdad ${ }^{23}$. Para comprender esta idea, conviene dilucidar en qué consisten los acomodos razonables.

${ }^{22}$ Si la norma de neutralidad cultural es en la práctica imposible de aplicar, es oportuno distinguir la neutralidad cultural de la neutralidad axiológica: "El imperativo de la neutralidad del Estado impone a este no el ser neutral en relación a la cultura o la lengua pública, sino de ser neutral en relación a las orientaciones axiológicas de los ciudadanos, en relación a sus creencias profundas de naturaleza religiosa, moral o filosófica". [L'impératif de neutralité de l'État impose à celui-ci, non d'être neutre à l'endroit de la culture ou de la langue publique, mais d'être neutre par rapport aux orientations axiologiques des citoyens, par rapport à leurs croyances profondes de nature religieuse, morale ou philosophique]. Stéphane CoURTOIs, "Le Québec face au pluralisme: un plaidoyer pour l'interculturalisme": Argument. Politique, société et histoire, vol. 13, n. ${ }^{\circ} 1$ (2010). Disponible en: http://www.revueargument.ca/article/2010-10-01/507-le-quebec-face-aupluralisme-un-plaidoyer-pour-linterculturalisme.html (13-6-2014).

${ }^{23}$ Laborde, Critical Republicanism. The Hijab Controversy and Political Philosophy, passim. 
Las raíces del acomodo razonable se encuentran en las ideas de igualdad y de discriminación. Constituye en su origen una noción jurídica que nace en los años setenta en el marco del Derecho estadounidense y en la década de los ochenta en el canadiense, siendo asociada inicialmente a la jurisprudencia del ámbito laboral y de la discriminación por motivos religiosos ${ }^{24}$. Desde entonces, la interpretación jurisprudencial del concepto de discriminación, fundamentalmente en relación a las discriminaciones indirectas, ha ido evolucionando y, en este proceso, la noción de acomodo razonable, además de consolidarse y extenderse a otras formas y fuentes de discriminación, ha ampliado su abanico de actores.

Toda sociedad democrática debe buscar mecanismos para evitar discriminaciones y en las actuales sociedades, donde poco a poco la diversidad cultural aumenta y se diversifica, se requiere una gestión capaz de encontrar mecanismos que eviten las discriminaciones que resultan de las diferencias culturales. Estas discriminaciones pueden ser el resultado de la adopción de una perspectiva sumamente formal de la igualdad, del sostenimiento de una doctrina que proclama la aplicación uniforme de la ley o de la adopción de normas jurídicas aparentemente neutras y no directamente discriminatorias. Frente a ello se presenta una doctrina alternativa que habilita una fórmula de flexibilidad, la del acomodo razonable, dirigida a combatir discriminaciones causadas por la aplicación estricta de una norma. El acomodo razonable es una obligación jurídica que emana del derecho a la no discriminación; esta obligación tiene por objeto garantizar que los ciudadanos, especialmente los que pertenecen a minorías, no se vean discriminados por motivo de sus creencias religiosas o sus prácticas culturales por parte de actuaciones públicas o privadas intencionales o involuntarias. Ahora bien, el acomodo razonable es un mecanismo que opera como una exención y que está relacionado con derechos individuales, no con la creación de un derecho colectivo.

Para comprender la aplicación práctica de un acomodo razonable es preciso tener en cuenta, al menos, las siguientes tres cuestiones. En primer lugar, el

${ }^{24}$ En diciembre de 1985, la Corte Suprema de Canadá admite por primera vez la existencia de una obligación de acomodo; el caso se refiere a una trabajadora de un comercio, miembro de la Iglesia adventista del séptimo día, que solicita que le sea reconocido un acomodo para conciliar su horario y calendario de trabajo con su religión. La Corte reconoce que el empleador tiene el derecho a abrir su negocio los sábados, pero que esta exigencia puede tener efectos discriminatorios de carácter indirecto sobre una trabajadora en tanto que restringe su libertad religiosa. Salvo perjuicios excesivos - “contraintes excessives"- el empleador no tiene derecho a impedir a la empleada practicar su religión, por tanto debe buscar un acomodo mediante la modificación de los horarios de trabajo. Commission ontarienne des droits de la personne c. Simpson-Sears, Jugements de la Cour suprême du Canada, 2 R.C.S. 536, 1985, pp. 554-555. 
acomodo puede ser un requerimiento que se manifiesta por la presencia tanto de acciones, por ejemplo, la existencia de condiciones arbitrarias, como de inacciones, por ejemplo, no haber adoptado medidas para evitar que los grupos desfavorecidos se vieran impedidos de acceder en condiciones de igualdad a servicios ofrecidos al resto de la población. En segundo lugar, el acomodo puede ser impuesto por un tribunal o incorporado a una norma y, en ambos casos, se trata de la imposición de medios que tienen como fin evitar la discriminación ${ }^{25}$. En tercer lugar, el acomodo razonable adopta diferentes formas.

Una ordenada clasificación de estas formas la encontramos en el trabajo de Eduardo Ruiz Vieytez, quien sistematiza seis posibles supuestos que - como él mismo reconoce - no agotan las posibilidades, pero nos dan una orientación ${ }^{26}$. Conviene advertir que esta ordenación puede aludir tanto a acomodos razonables como a ajustes concertados, ambos considerados prácticas de armonización intercultural ${ }^{27}$. Primero, acomodos en el ámbito de la vestimenta o de la apariencia física. Estos pueden darse, por un lado, en el medio laboral donde se exige vestir determinados uniformes o portar indumentarias específicas (bomberos, policías, personal en centros de salud) que pueden llegar a ser incompatibles con prendas que tienen una significación religiosa (velo musulmán, Kipá judío o turbante sij —sikh-); por otro lado, en el sector educativo en el que se presentan un sinnúmero de situaciones (a título de ejemplo podemos mencionar la polémica que se deriva del debate entre seguridad y respeto a la libertad religiosa, sien-

${ }^{25}$ José Woehrling, "La libertad de religión, el derecho al acomodamiento razonable y la obligación de neutralidad religiosa del Estado en el derecho canadiense": Revista catalana de dret públic, n. ${ }^{\circ} 33$ (2006), pp. 1-32.

${ }^{26}$ Eduardo RuIz VIEYTEZ, "Las prácticas de armonización como instrumento de gestión pública de la diversidad religiosa": Documentos del Observatorio del pluralismo religioso en España, n. 4 (2012). La clasificación del profesor Ruiz Vieytez está pensada para acomodos en el ámbito religioso, pero resulta también válida para acomodos de otras particularidades culturales e incluso para convicciones profundas de corte secular como son las propias de los vegetarianos o los ecologistas.

${ }^{27}$ Estas denominaciones son elaboradas por Gérard Bouchard y Charles Taylor quienes subrayan que el ajuste concertado designa al conjunto de prácticas encaminadas a conseguir acuerdos amigables de manera informal entre el personal de las instituciones públicas o privadas y el resto de la ciudadanía (alumnos, pacientes, empleados, clientes, etc.). Esta noción difiere del concepto de acomodo razonable en cuanto que sus prácticas pretenden evitar el recurso a los tribunales y a normas jurídicas y dar preferencia a la voz ciudadana. Los ajustes concertados se fundan en el ideal de que la gestión de la vida en común debe ser lo más armoniosa posible y de que la concertación es inherente a la esfera ciudadana. El concepto de armonización intercultural denomina al conjunto de prácticas tanto de acomodo razonable como de ajuste concertado que versan sobre diferencias culturales. BOUCHARD Y TAYLOR, Fonder l'avenir. Le temps de la conciliation, passim. 
do el caso Multani en Quebec uno de los más conocidos ${ }^{28}$ ); finalmente, los acomodos sobre vestimenta también pueden ser demandas derivadas de situaciones de acceso a determinados servicios (realizar funciones judiciales, ejercer el derecho a voto, acceder a un medio de transporte). Segundo, acomodos en relación al tiempo. Aquí el acomodo consiste en solicitar la adaptación de horarios o calendarios (respetar el descanso en días sagrados, respetar las festividades de ritos y cultos específicos como el ayuno durante el Ramadán, el inicio del año chino, el Thanksgiving que celebran millones de estadounidenses y canadienses). Tercero, acomodos en el ámbito de la alimentación, donde la petición consiste en la adaptación de menús o cartas gastronómicas en virtud de creencias religiosas o seculares (se demanda esta adaptación en entidades públicas como son prisiones, escuelas, hospitales, cuarteles o en espacios privados como son los medios de transporte). Los solicitantes pueden ser vegetarianos o personas cuya religión no les permite comer carne de vaca o de cerdo, por ejemplo. En este supuesto, la demanda de acomodo requiere, a diferencia de los casos anteriores, de una acción positiva ya que no es suficiente la excepción a la norma. Cuarto, acomodos en la esfera de la utilización de espacios públicos donde se solicita su adaptación para actividades de culto o similares, o se demanda la excepción en la regulación pública o privada que impide o dificulta el ejercicio de la libertad religiosa (festividades o ritos religiosos en la vía pública, reserva de espacios por periodos u horarios determinados para personas que pertenecen a determinadas confesiones religiosas). Quinto, acomodos en relación al acceso a servicios públicos. Estas demandas se presentan cuando ciudadanos que pertenecen a minorías quieren hacer uso de o acceder a determinados servicios públicos (por ejemplo, servicios al Estado a cambio de obligaciones militares, exigencias de juramentos para el acceso a funciones públicas, registros corporales o controles de seguridad, excepciones en la forma de llevar a cabo los exámenes de conducción - hay confesiones que impiden reunirse en un espacio cerrado como es un coche a personas de diferente género-). Sexto y último, acomodos en el ámbito de los enterramientos donde las demandas están relacionadas con los espacios y los requisitos sanitarios.

${ }^{28}$ En marzo de 2006, la Corte Suprema de Canadá permite que un joven sij (sikh) de Québec lleve un kirpán — daga ceremonial de profunda simbología - a la escuela. La Corte declara que la prohibición de este acto por parte del Tribunal de Apelación va en contra de la libertad religiosa y que llevar dicho objeto no afecta a la seguridad de otros alumnos. Ordena, sin embargo, que el alumno Gurbaj Singh Multani, quien vive en Montreal, lleve su cuchillo envuelto en un estuche de tela bajo su ropa. 
De la anterior descripción se desprende que el acomodo razonable no es tanto el resultado de una formulación legislativa cuanto de una forma de entender el derecho a la igualdad y la no discriminación. El acomodo razonable es la consecuencia jurídica de entender el principio de igualdad como una exigencia que permite un trato diferencial sin que necesariamente tenga que interpretarse como preferencial; no es un privilegio, como algunos sostienen, sino una excepción que permite restablecer equilibrios y procurar una igualdad de resultados frente a la generalización de un trato uniforme ${ }^{29}$. Gérard Bouchard en su escrito Qu'est-ce que l'interculturalisme? ${ }^{30}$ subraya que los acomodos no son privilegios, no han sido concebidos únicamente para los inmigrantes y tampoco dan rienda suelta a sus valores, creencias o prácticas contrarias a las normas fundamentales de la sociedad. El objetivo es proteger a los ciudadanos pertenecientes a determinados colectivos de prácticas discriminatorias que resultan de normas jurídicas ${ }^{31}$. En esta misma lógica resulta recomendable también tener presente que el hecho de que la demanda de acomodo sea contemplada como una consecuencia jurídica de una específica forma de concebir el principio de igualdad es lo que ha facultado que esta exigencia pueda extenderse a otros motivos recogidos por las normas en las que se prohíbe la discriminación por discapacidad, sexo, edad, origen nacional, entre otros.

Si el objetivo del acomodo razonable es regular las discrepancias y llegar a resoluciones que tengan como fundamento la igualdad en la diferencia, entonces estamos ante un instrumento que facilita la interacción y valora la reciprocidad, aun cuando su vocación primera sea la de evitar la discriminación ${ }^{32}$. Estos dos valores, interacción y reciprocidad, cobran especial relevancia principalmente en relación a la convivencia en un marco de pluralidad cultural donde el acomodo razonable puede constituirse en una herramienta de gran utilidad para la gestión

\footnotetext{
${ }^{29}$ Marie McANDREw, "Pour un débat inclusif sur l'accommodement raisonnable": Éthique Publique, vol. 9, n. ${ }^{\circ} 1$ (2007), p. 154.

${ }^{30}$ Publicado en francés en Gérard Bouchard, "Qu'est-ce que l'interculturalisme?": Revue de droit de McGill, n. 56 (2011), pp. 395-433; y en inglés en Alain-G. GAGnon y José María Sauca (eds.), Negotiating Diversity: Identity, Pluralism and Democracy, Peter Lang, Brussels, 2013.

${ }^{31}$ Véase la sentencia Thlimmenos contra Grecia, de 6 de abril de 2000, en la que el Tribunal Europeo de Derechos Humanos hace una interpretación que amplía la hasta ahora concepción del principio de no discriminación y se acerca a la llamada discriminación por igualación o discriminación por indiferenciación.

${ }^{32}$ Myriam Jezequel (dir.), Les accommodements raisonnables: quoi, comment, jusqu'où? Des outils pour tous, Éditions Yvon Blais, Québec, 2007.
} 
de la diversidad ${ }^{33}$. Si un acomodo no favorece la coexistencia, sino que la obstaculiza, entonces no es razonable y no puede ser considerado en los términos expuestos. El profesor José Woehrling ha señalado en diversos trabajos que la política del acomodo tiene como objetivo fundamental:

[F]avorecer la inclusión de las minorías y de los inmigrantes en la sociedad de acogida, especialmente eximiéndoles de las normas que entrañan una discriminación directa o indirecta. Las políticas del acomodo y del pluralismo se sustentan sobre la apuesta de que el reconocimiento de la diferencia y las adaptaciones que se consienten a las minorías facilitarán, a medio o a largo plazo, su armoniosa integración en la sociedad ${ }^{34}$.

En relación a la reciprocidad, Gérard Bouchard sostiene que si los Estados liberales no pueden establecer una estricta neutralidad estatal y que si las mayorías tienen derecho a ciertas ventajas, es necesario corresponder mediante el reconocimiento a las minorías del derecho a un mecanismo de corrección que les permita salvaguardarse de eventuales abusos por parte de la mayoría ${ }^{35}$.

La sucinta exposición hasta aquí trazada no nos debe hacer perder de vista que las demandas de acomodo son admisibles únicamente si las medidas que se adoptan son razonables y, en consecuencia, no constituyen un "perjuicio excesivo"36 tal y como lo expresó la propia Corte Suprema de Canadá en su sentencia del caso Sears-Simpson. Esto quiere decir que un acomodo debe quedar circunscrito a los límites de la razón y “en este contexto 'perjuicio excesivo' y 'razona-

${ }^{33}$ Pierre AnCTIL, “Quel accommodement raisonnable?": Éthique Publique, vol. 9, n. ${ }^{\circ} 1$ (2007), pp. 186-191.

34 "La politique de l'accommodement a essentiellement pour but de favoriser l'inclusion des minorités et des immigrants dans la société d'accueil, notamment en leur permettant de se soustraire aux normes qui entraînent une discrimination directe ou indirecte à leur endroit. Les politiques de l'accommodement et du pluralisme reposent sur le pari que la reconnaissance de la différence et les adaptations qui sont consenties aux minorités faciliteront, à moyen et à long terme, leur intégration harmonieuse dans la société". José WoeHrLing, "Neutralité de l'État et accommodements: convergence ou divergence?": Options Politiques (Septembre 2007), p. 25. La cita anterior nos abre la vía para aclarar que cuando se alude a los acomodos razonables y a la diversidad no se está haciendo referencia únicamente a los nuevos inmigrantes en una determinante sociedad, también se incluyen a miembros de comunidades culturales de largo asentamiento, incluso más antiguo que el grupo cultural mayoritario.

${ }^{35}$ Gérard Bouchard, L'Interculturalisme, Boréal, Montréal, 2012, p. 128.

${ }^{36} \mathrm{El}$ término en inglés es undue hardship y en francés contrainte excessive. En español, algunos lo han traducido como "penalidad excesiva" y otros como "inconveniente excesivo". 
bilidad' son dos maneras diferentes de expresar el mismo concepto" ${ }^{37}$. Por tanto, el acomodo no debe ser un castigo, sino la obligación de ofrecer una solución mediante la búsqueda de un entendimiento entre quien reclama el respeto a su convicción profunda y aquel a quien se reclama dicho arreglo. Ambas partes "deben comprometerse a realizar un esfuerzo significativo, serio y sincero en la búsqueda del acomodo"38.

La igualdad entendida como trato diferencial sin ser preferencial o como principio de derecho a la diferencia sin que ello signifique diferencia en los derechos, tiene su corolario en la teoría política, especialmente en los defensores del paradigma del reconocimiento; es una propuesta que interpreta al reconocimiento como un diálogo continuo a través del cual transcurre, en la búsqueda de acuerdos, el eje de la reciprocidad. De acuerdo con esta perspectiva, una ética del reconocimiento de culturas minoritarias y de la diferencia constituye no solo una exigencia moral y política sino también un asunto de justicia social ${ }^{39}$. Como ya se ha señalado, no debe interpretarse como asignación de privilegios el hecho de que un mismo derecho pueda suscitar en algunas ocasiones dos tratamientos diferentes cuando de lo que se trata es de corregir un defecto en la aplicación de una ley o de un reglamento. Los autores mencionados a pie de página consideran agotado el modelo de coexistencia configurado de acuerdo con los principios de homogeneidad e igualdad abstractas, y reclaman una igualdad que se realice en medio de la diferencia reconocida, ya que consideran que hay tratamientos que pueden ser diferenciales sin ser preferenciales ${ }^{40}$. Para avanzar en la lógica de la igualdad se requiere valorar las diferencias y para asegurar las libertades individuales es necesario instaurar mecanismos de convivencia en un marco de pluralidad cultural. Por ello, Maclure asegura que los acomodos $-\mathrm{y}$ junto con ellos las políticas públicas de la diversidad cultural que sigan esta misma lógicapueden considerarse "moralmente justos y políticamente sabios"

${ }^{37}$ Pierre Bosset, "Limites de l'accommodement: le droit a-t-il tout dit?": Éthique Publique, vol. 9 , n. ${ }^{\circ} 1$ (2007), p. 168.

${ }^{38}$ Miren GoRROtXATEGUI AzURMENDI, "El interculturalismo quebequés en la encrucijada. De la crisis de los acomodamientos razonables a la Comisión Bouchard-Taylor": Revista de Estudios Políticos, n. ${ }^{\circ} 150$ (2010), p. 183.

${ }^{39}$ Pensadores representativos son Joseph Carens, Nancy Fraser, Bhikhu Parekh, Charles Taylor, James Tully e Iris Marion Young.

${ }^{40}$ Bhikhu Parekn, Rethinking Multiculturalism: Cultural Diversity and Political Theory, Palgrave Macmillan, Basingstoke, 2000.

${ }^{41}$ Jocelyn Maclure, "Un défense de multiculturalisme comme morale politique", en Myriam JÉZÉQuEL (dir.), La justice à l'épreuve de la diversité culturelle, Éditions Yvon Blais, Montréal, 2007, p. 77. 
en escritos recientes algunos autores han señalado que una política del reconocimiento es hoy en día una condición fundamental de las democracias culturalmente diversas, aunque insuficiente para el proceso de profundización de la calidad democrática ${ }^{42}$.

El hecho de que numerosas normas, en apariencia neutras y universales, reproduzcan visiones del mundo, valores del grupo mayoritario, códigos implícitos o reglas informales que no están formulados explícitamente pero que están extendidas y se aplican muchas veces ocultas en el discurso de la neutralidad, es lo que justifica que en el marco de la teoría política los acomodos razonables también puedan ser leídos desde las lentillas de la libertad como no dominación. Esta lectura no tiene cabida en el marco de un republicanismo que aboga por un asimilacionismo coercitivo como ruta para la coexistencia en la diversidad; pero sí puede darse en el marco de un republicanismo pluralista e inclusivo que respeta los diversos rasgos diferenciales con el fin de que los distintos grupos culturales puedan, por una parte, disfrutar de la misma oportunidad que tienen los ciudadanos con los que conviven de vivir el tipo de vida que sus convicciones profundas les aconsejan practicar y, por otra parte, de no estar sometidos a exigencias legales que impliquen una violación de sus convicciones y modos de vida.

Esta lectura de los acomodos razonables y las prácticas de armonización intercultural desde la libertad como no dominación encuentra considerables justificaciones en el trabajo Républicanisme critique vs républicanisme conservateur: repenser les accommodements raisonnables desarrollado por Cécile Labor$\mathrm{de}^{43}$. En los casos en los que la ley y la esfera pública no son cultural y religiosamente neutras, ciertos acomodos razonables a favor de miembros de minorías pueden ser demandas de lo que la autora llama justicia republicana ${ }^{44}$. El acomodo razonable, en la medida en que pretende el establecimiento de la igualdad, es compatible con lo que Laborde considera un republicanismo bien entendido; aquel que acepta la conveniencia de una mirada crítica sobre su propio contexto histórico cultural ${ }^{45}$. Este modelo de aproximación crítica "ha estado ausente

\footnotetext{
${ }^{42}$ Alain-G. Gagnon, La era de las incertidumbres, Tirant lo Blanch, Valencia, 2013.

${ }^{43}$ Cécile LaBorde, "Républicanisme critique vs. Républicanisme conservateur: repenser les 'accommodements raisonnables"': Critique Internationale, n. 44 (2009), pp. 19-33.

${ }^{44}$ Ibid., p. 20.

${ }^{45}$ Esta idea se encuentra también en las teorías de la postcolonialidad que sostienen que "el Estado no puede ser culturalmente neutro porque si es neutro, objetivamente, favorece a la cultura dominante". Boaventura DE SOUSA SANTOS, "Las paradojas de nuestro tiempo y la plurinacionalidad", en Alberto Acosta y Esperanza Martínez (comps.), Plurinacionalidad. Democracia en la diversidad, Abya-Yala, Quito, 2009, p. 40.
} 
del debate republicano francés", pero lo encontramos "en el corazón de la redefinición de la doctrina de la integración de minorías en América del Norte, especialmente en Quebec" ${ }^{\prime 4}$.

La autora desaprueba al republicanismo que llama oficial, supuestamente neutro y laico, y reconstruye lo que ha denominado un republicanismo crítico. En su reproche denuncia que en Francia ha habido un consenso republicano forjado sobre tres grandes principios que constituyen el armazón conceptual del concepto de laicidad. Primero, una misma ley laica para todos, principio que deriva del ideal de igualdad republicana que afirma que la ley debe aplicarse a todos y que debe primar sobre las reglas religiosas. Este principio, afirma Laborde, corre el riesgo de llevar a una confusión respecto de la neutralidad. Segundo, la no sumisión a la voluntad de otro, principio que deriva del ideal republicano de la libertad de autonomía y que inspira la crítica feminista de ciertas prácticas musulmanas como la del uso del velo. Este principio tiene como riesgo un exceso de paternalismo, porque si la máxima de la no dominación es central para el republicanismo - al menos el pluralista e integrador o crítico- no queda claro que la interpretación que hace el consenso republicano francés sea coherente dado que, por ejemplo, se pretende emancipar a las mujeres pertenecientes a determinadas minorías mediante la coerción en lugar de preguntarse sobre las condiciones políticas, sociales y culturales necesarias para la no dominación, algo que el republicanismo crítico sí lleva a cabo. Laborde señala que esta actitud puede derivar en una confusión entre dominación masculina y dominación postcolonial. El tercer principio consiste en el deber de asimilación; proviene del ideal republicano de fraternidad y se encuentra determinado por los fundamentos morales, culturales y políticos de la comunidad de ciudadanos franceses. Es lógico, como ya se mencionó anteriormente, que deben respetarse algunas de las prácticas y consensos de la sociedad de acogida (por ejemplo, el uso de la lengua), pero no debe caerse en la confusión entre moralidad pública (por ejemplo, los valores de la República) y los prejuicios culturales de la comunidad de acogida, en este caso, la de "la cultura francesa 'catho-laïque' que prescribe los comportamientos públicos y privados" 47 .

46 "Cette approche critique est au cœur de la redéfinition de la doctrine de l'intégration des minorités en Amérique du Nord, et notamment au Québec". LABORDE, "Républicanisme critique vs. Républicanisme conservateur: repenser les 'accommodements raisonnables", p. 20. La autora lleva a cabo su análisis sobre la base de una aproximación crítica al republicanismo francés, especialmente a la luz de la Comisión Stasi.

${ }^{47}$ Ibid., p. 26. 
Vistos de esta manera, estos principios se encuentran en la base de la crítica a los acomodos de prácticas culturales y religiosas de las minorías; denuncian que no es posible considerarlos razonables porque permiten a cada comunidad vivir de acuerdo a sus valores, e incluso aplicar su propio derecho, lo que va en detrimento de la libertad, la igualdad y la fraternidad. Sin embargo, este discurso, denuncia Laborde, "puede radicalizar peligrosamente al republicanismo" y conducirle por la vía comunitaria y conservadora. En consecuencia, conviene apostar por un republicanismo crítico, pluralista e inclusivo. Este parte de la aceptación de que la esfera pública no es cultural y religiosamente neutra, como no lo son tampoco las normas y las prácticas, y que ante la eventualidad de acciones discriminadoras es posible considerar convenientes ciertos acomodos razonables siempre que respeten, como queda claro en el Informe de la Comisión Bouchard-Taylor, determinados principios como son la igualdad de derechos y la igualdad entre hombres y mujeres ${ }^{48}$. Desde esta perspectiva, en entornos culturalmente diversos, los acomodos razonables pueden ser leídos desde la libertad como no dominación.

A lo largo de su libro Critical Republicanism. The Hijab Controversy and Political Philosophy, Laborde pretende sacar a la luz las imperfecciones del republicanismo francés y su supuesto vínculo con un republicanismo ideal. Esta labor la lleva poniendo en cuestión la articulación entre hechos y normas, entre realidades sociales e ideales filosóficos. El alcance de este ejercicio es altamente significativo, dado que su reflexión se inscribe en una labor analítica mucho más profunda que está directamente vinculada a una crítica que ella realiza hacia las formas más convencionales de hacer teoría política y que se caracterizan por una reflexión insuficiente sobre la relación entre prescripciones normativas y hechos sociales. La autora distingue, en el plano metodológico, entre las aproximaciones analíticas (por ejemplo, abstractas y normativas) de los textos y de las prácticas, y los acercamientos sintéticos o contextualistas, e intenta evitar los inconvenientes de tratar separadamente a estos dos tipos de enfoques. Las orientaciones normativas y analíticas deben tomar siempre en cuenta el contexto. El objetivo consiste en que la teoría normativa integre en sus reflexiones las relaciones entre normas ideales y normas prácticas, normas legales y actitudes sociales e incluso normas culturales y relaciones de poder ${ }^{49}$. Es en este marco que ella desmonta el modelo del republicanismo francés y reconstruye el llamado republicanismo crítico.

${ }^{48}$ Véase Bouchard y TAYlor, Fonder l'avenir. Le temps de la conciliation, passim.

${ }^{49}$ Laborde, Critical Republicanism. The Hijab Controversy and Political Philosophy, pp. 8-9. 


\section{¿QUIÉN DECIDE Y CÓMO SE DECIDEN LAS PRÁCTICAS CULTURALES?}

En este último apartado, y siguiendo el hilo conductor mantenido a lo largo de las páginas anteriores, dirigimos la atención a dos cuestiones centrales en el discurso de la gestión de la diversidad cultural. Ambas tienen que ver con los grupos y prácticas que pueden ser objeto de reconocimiento y acomodo. La primera dirige su atención al agente decisor — quién decide—, en tanto que la segunda se ocupa del procedimiento, — cómo se decide—, esto es, cuál es el procedimiento en base al cual se adoptarán las decisiones ${ }^{50}$.

Para responder ambas cuestiones hay que tener claro que, si bien las sociedades deben aspirar a ser plurales, abiertas y dinámicas, ello no significa que las demandas de acomodo deban atenderse en todos los casos. Los comportamientos, tanto de la sociedad de acogida como de los grupos minoritarios provenientes de la inmigración o los asentados en el mismo territorio desde hace tiempo, no deben percibirse como incuestionables y permanentes. En esta lógica hay dos temas centrales a considerar a la hora de intentar ponerse de acuerdo sobre quién decide qué prácticas de los distintos grupos culturales pueden ser tomadas en consideración y cuál es el proceso a través del cual se adoptará esta decisión. En primer lugar, y como ya se señaló anteriormente, la necesaria distinción entre, por un lado, máximas que comportan principios universales y que constituyen el piso sobre el que se debe edificar el proyecto de vivir juntos en la diversidad (sociedad democrática, igualdad entre hombres y mujeres y garantía de derechos y libertades $)^{51}$. Estas premisas no están a discusión, ya que constituyen un punto de partida. Y, por otro lado, tener claridad sobre las conductas y reglas que reproducen los valores de la cultura mayoritaria (como denuncia Laborde con su expresión catho-laïque). Es conveniente que a la hora de determinar quién decide y cómo se decide se detecte bien cuáles de estos valores son imprescindibles para la convivencia y cuáles son muchas veces injustamente impuestos a los miembros de una comunidad.

En segundo lugar, para determinar quién decide y cómo se decide una petición de ajuste concertado, en su modalidad de acomodo razonable o de práctica de armonización intercultural, deben tomarse en cuenta, al menos, las siguientes orientaciones. Por una parte, debe considerarse el contexto en el que se llevan a cabo; por otra, las demandas tienen que cumplir con el criterio de la razonabili-

${ }^{50}$ James Tully, "La conception républicaine de la citoyenneté dans les sociétés multiculturelles et multinationales": Politiques et Sociétés, vol. 20, n. ${ }^{\circ} 1$ (2001), pp. 123-146.

${ }^{51}$ Estas condiciones quedaron perfectamente explícitas en el Informe de la Comisión Bouchard-Taylor. BOUCHARD y TAYLOR, Fonder l'avenir. Le temps de la conciliation, passim. 
dad; y finalmente, debe dedicarse un importante esfuerzo a crear las condiciones para fomentar que sea a través del diálogo la forma en que se llegue a los acuerdos.

Detengámonos brevemente en estas tres últimas orientaciones. Recordemos que la "idea central que se encuentra en la raíz del concepto de acomodo razonable es que un Estado democrático permita a cada uno y a cada una participar plenamente y en condiciones de igualdad en la vida en sociedad" y si esta sociedad es culturalmente diversa, entonces se debe apostar por "la igualdad en la diversidad" 52 . Para comprender las particularidades, concretar un tratamiento diferente y promover la inclusión en la sociedad del mayor número de miembros, resulta necesario que sean consideradas ciertas condiciones específicas propias del entorno en el que se está llevando a cabo el proceso (especificidades religiosas, lingüísticas, culturales, entre otras).

Respecto de la segunda orientación es conveniente insistir en que las demandas de acomodo tienen que ser razonables y solo serán plausibles si:

[Si] respetan los derechos de otros; se llevan a cabo conforme a la ley; se adoptan en consonancia con los valores fundamentales de la sociedad de acogida o mayoritaria; no trastornan el funcionamiento habitual de un organismo o una institución; no entrañan costes excesivos; y van en el sentido de integrar al demandante ${ }^{53}$.

El ignorar estas cuestiones conduce a propagar imágenes distorsionadas que, en ocasiones, alcanzan repercusiones mediáticas con consecuencias no siempre alentadoras para el objetivo de vivir conjuntamente en nuestra diversidad. Si el acomodo razonable se integra en una actitud de lucha contra la discriminación y la gestión de la diversidad, hay que evitar que la opinión pública tenga una idea tergiversada del objetivo de dichos acomodos porque, si no es así, fácilmente se puede desvirtuar y hacer creer que dicha gestión se limita a la bús-

52 'L'idée centrale qui est à l'origine du concept de l'accommodement raisonnable est qu'un Etat démocratique doit permettre à chacun et chacune de participer pleinement et sur un pied d'égalité à la vie en société...l'égalité dans la diversité". Pierre Bosset y Marie-Claire FoBLETS, "Le Québec et l'Europe face au besoin d'accommoder la diversité: disparité des concepts juridiques, convergence des résultats?", en Accommodements institutionnels et citoyens: cadres juridiques et politiques pour interagir dans des sociétés plurielles, Tendances de la cohésion sociale $\mathrm{n}^{\circ}{ }^{\circ} 21$, Conseil de l'Europe, Bruxelles, 2009, p. 37.

53 "Si elles respectent les droits d'autrui; elles sont conformes à la loi; elles sont en accord avec les valeurs fondamentales de la société d'accueil; elles ne bouleversent pas le fonctionnement normal d'un organisme ou d'une institution; elles n'entraînent pas des coûts excessifs; et elles vont dans les sens de l'intégration du demandeur". BOUCHARD, L'interculturalisme, p. 129. 
queda frenética de acomodos. El informe de la Comisión Bouchard-Taylor denuncia claramente esta situación ${ }^{54}$.

La tercera orientación es la que pone el acento en el diálogo. Es indudable que las culturas se configuran con creencias y principios, y que debiéramos abandonar la lógica de expresarnos en términos de superioridad e inferioridad (civilizados y salvajes son los vocablos de nuestra propia herencia intelectual); pero esto no significa que tenga que asumirse que todos los componentes de una cultura tengan valor y que se debe intentar acomodar cualquier supuesto. Hay creencias en los grupos culturales mayoritarios y en los minoritarios que son indefendibles en un Estado de Derecho y uno de los caminos para hacerles frente de manera democrática debe ser la crítica y la deliberación. Como bien afirma Velasco, las reclamaciones y exigencias de las minorías "no son el punto de llegada de la política democrática, sino un punto de partida. Las reivindicaciones en nombre de las peculiaridades culturales o de las identidades no están por encima del escrutinio democrático" 55 . Ante la eventualidad de un conflicto entre individuos y grupos, el procedimiento para resolverlo debe corresponder a normas democráticas, especialmente "medidas deliberativas como la mediación, el compromiso y la negociación directa, dejando en lo posible la iniciativa y la autonomía a las partes en cuestión", las medidas jurídicas y el recurso a derechos específicos son opciones de último recurso, lo que conviene impulsar es "la deliberación, el entendimiento mutuo y, en general, el diálogo" 56 . La única garantía para que no haya intromisiones arbitrarias la ofrece la lógica democrática, porque es la que permite que los ciudadanos distingan "las interferencias justas de las arbitrarias mediante amplios procesos públicos de participación y de deliberación colectiva" ${ }^{\prime \prime}$.

El iraní Ramin Jahanbegloo en su alegato contra los fundamentalismos sostiene que el diálogo no solo es la mejor vía para resolver los conflictos y "promover una percepción compartida de las cosas", sino también para encauzar

${ }^{54}$ Me he ocupado de ello en Isabel Wences, "Cuatro lecciones de la Comisión BouchardTaylor: Acomodos razonables, pluralismo integrador, laicidad abierta y participación ciudadana", en Pedro Chaves, Carlos Prieto y René Ramírez (eds.), Crisis del capitalismo neoliberal, poder constituyente y democracia real, Traficantes de sueños, Madrid, 2013.

${ }_{55}^{5}$ Juan Carlos Velasco, "La noción republicana de ciudadanía y la diversidad cultural": Isegoría, n. 33 (2005), p. 203.

${ }^{56}$ Alain-G. GAGNON y Raphael JACOVINO, "El proyecto intercultural quebequense: expandiendo los límites de la ciudadanía", en Alain-G. GAGNon (comp.), Quebec: Estado y Sociedad, Universidad de Guadalajara, Guadalajara (México), 2003, p. 401.

${ }^{57}$ Sergio Ortiz Leroux, "Democracia liberal y democracia republicana: ¿ruptura o continuidad?”: Isotimia. Revista Internacional de Teoría Política y Jurídica, n. ${ }^{\circ} 5$ (2011), p. 60. 
mediante la "escucha del otro" el reconocimiento de la diversidad; sin diálogo la vida en común en contextos de diversidad es inalcanzable y "sin respeto por la diversidad, el diálogo es inútil" ${ }^{58}$. En esta misma lógica, Tariq Ramadan sostiene que una actitud justa y razonable — así como políticamente responsable - consiste en escuchar y dialogar con los ciudadanos de otros orígenes que ya viven en el mismo territorio, y que muchas veces acompañan a los recién llegados en su proceso de instalación. Nuestras sociedades tienen necesidad de este diálogo y deben darse las condiciones para que los puntos de vista se confronten en un marco regulado capaz de contener los excesos, sin que ello signifique ocultar los miedos o las tentaciones de rechazo. Los acomodos razonables y las prácticas de armonización intercultural no son privilegios, como ya se indicó, sino obligados procesos de una sociedad que pretenda ser fiel a sus ideales democráticos:

Más libertad para unos debería querer decir más libertad para todos. Esto es justamente lo opuesto a esa falsa ecuación que hace pensar que la restricción de las libertades de los 'recién llegados' o 'minorías' quiere decir la preservación, o incluso el incremento, de las libertades de la mayoría. Es exactamente lo contrario: cuando alguien atenta contra la libertad de conciencia de un segmento de la sociedad, por mucho que sea (o que se perciba) minoritario, es la libertad de todos la que se vulnera ${ }^{59}$.

La dimensión jurídica que acompaña a los acomodos razonables, no debe hacernos olvidar que la indispensable función de los tribunales es un último recurso, ya que lo fundamental es sentar las bases para que sea la acción de los ciudadanos la que intente resolver mediante el diálogo y de manera amigable e informal los desacuerdos que pueden presentarse entre el personal de las instituciones públicas o privadas y el resto de la ciudadanía. Esta premisa coincide con la idea del republicanismo pluralista e inclusivo de construir sistemas alternativos de diseño institucional que, enfatiza Philip Pettit, estimulen el comporta-

${ }^{58}$ Ramin Jahanbegloo, Elogio de la diversidad, Arcadia, Barcelona, 2007.

59 "Plus de liberté pour les uns doit vouloir dire plus de liberté pour tous. C'est ici l'exact opposé de cette fausse équation qui laisserait penser que la restriction des libertés des 'nouveaux venus' ou 'des minorités' voudraient dire la préservation, voire l'augmentation, des libertés de la majorité. C'est exactement le contraire: quand on atteint à la liberté de conscience d'un pan de la société, quelque minoritaire qu'il soit (ou soit perçu), c'est à la liberté d'être de tous que l'on porte atteinte". Ramadan TARIQ, "Accommodements pour les minorités ou accommodements pour tous et chacun. Réussir le 'vivre-ensemble' dans des sociétés plurielles", en Accommodements institutionnels et citoyens: cadres juridiques et politiques pour interagir dans des sociétés plurielles, Tendances de la cohésion sociale n. ${ }^{\circ}$ 21, Conseil de l'Europe, Bruxelles, 2009, p. 181. 
miento cooperativo a través del cultivo de la virtud cívica, en lugar de inspirar tan solo sistemas represivos que castiguen el comportamiento desviado de la norma legal ${ }^{60}$.

En suma, el proyecto de vivir juntos respetando nuestras diferencias no puede ser construido fuera del proceso social y político, sino a través de la interacción, de los acercamientos, de los intercambios, de las iniciativas conjuntas, del diálogo y, a través de este, de la construcción de acuerdos entre ciudadanos. Y este ejercicio debe llevarse a cabo en las mejores condiciones posibles de no dominación ${ }^{61}$. Un convencimiento similar se desprende de las palabras de Linda Cardinal y Marie-Joie Brady, quienes advierten que entre las condiciones que deben existir para que los ciudadanos puedan realizar un diálogo plural en condiciones de no dominación están, en primer lugar, la de reconocer a todos los ciudadanos la libertad de cambiar las reglas del juego constitucional del reconocimiento mutuo y de la asociación a medida que van transformándose las identidades. En segundo lugar, todos deben poder participar en la toma de decisiones, ya que las decisiones que afectan a la comunidad deben ser tomadas, a través de medidas justas y equitativas de deliberación, por el conjunto de los ciudadanos, aun cuando se sabe que la opinión de algunos puede quedar excluida de la decisión final. No obstante, "en un contexto de no dominación, los grupos saben que podrán eventualmente reactivar el diálogo plural”"62.

Por último, otro dato a tener en cuenta cuando se trata de encontrar la mejor manera de organizar nuestra convivencia en un entorno culturalmente diverso es que la fórmula del acomodo presenta algunas dificultades, especialmente si se trata de la relación entre grupos mayoritarios y grupos minoritarios, ya que aquí la fórmula del acomodo puede conducir a la presencia de una lógica jerárquica en las relaciones de poder que pondría en duda la legitimidad de los actores políticos. Ante esta posibilidad, algunos autores proponen afianzar la cooperación de tal manera que en la vida común esté presente "una relación de igual a igual" donde el grupo minoritario no sea percibido como un "pedigüeño" solicitando acomodo, sino como un socio con el que se dialoga y cuya relación se funda "sobre un conjunto de principios respetuosos del pluralismo comunitario, del

${ }^{60}$ Philip Pettit, Republicanismo. Una teoría sobre la libertad y el gobierno, Paidós, Barcelona, 1999. Véase especialmente cap. 7.

${ }^{61}$ James Tully, "Introduction", en Multinational Democracies, Cambridge University Press, Cambridge, 2001.

${ }^{62}$ Linda CARDINAL y Marie-Joie BRADY, "Ciudadanía y federalismo en Canadá: una relación difícil", en Alain-G. GAGNON (dir.), El federalismo canadiense contemporáneo. Fundamentos, tradiciones e instituciones, Tirant lo Blanch y Generalitat de Catalunya, Valencia, 2010, p. 473. 
pluralismo ideológico y, por qué no, del pluralismo jurídico" ${ }^{3}$. Lo fundamental en el debate sobre quién y cómo se deciden las prácticas culturales que deben ser objeto de reconocimiento es encontrar un equilibrio más armonioso entre las fuerzas políticas, a fin de que los miembros de los grupos minoritarios tengan posibilidades de llevar a cabo sus preferencias de manera comparable a los propios de los grupos mayoritarios. La meta a alcanzar con la búsqueda de este equilibrio es renovar el "vínculo de confianza intercomunitaria" 64 y habilitar a los grupos minoritarios para que puedan dotarse de los instrumentos necesarios.

Llegados a este punto habría que preguntarse si este proyecto encaja con una noción liberal de la libertad o si se encuentra más cómodo bajo el manto de la libertad en el sentido republicano que aquí se ha esbozado, donde la no dominación pretende combatir la condición de subordinación y de sometimiento a la voluntad de otro, sean individuos o comunidades. Sabemos que una situación de dominación se presenta cuando alguien puede interferir de manera arbitraria en las elecciones de aquel al que se domina. Esta interferencia puede ser a partir de un interés u opinión no necesariamente compartidos por la persona afectada. La pregunta que se hace Alain G. Gagnon sobre cómo procurar a los grupos minoritarios la garantía de su libertad y forzar a los mayoritarios a tomar en consideración sus reivindicaciones legítimas, encuentra más eco en la defensa de una idea de libertad entendida como ausencia de dominación y de acuerdo con la cual las acciones y las decisiones no dependen de la voluntad arbitraria de otro, es decir, no se encuentran limitadas por estos.

\section{REFLEXIONES FINALES}

La diversidad cultural existe desde tiempos remotos, pero no siempre se ha considerado un valor convivir reconociendo la diferencia cultural. Durante siglos la supremacía de un grupo sobre otros ha sido la constante de nuestras relaciones $\mathrm{y}$, es por ello, que hoy cobra importancia reflexionar sobre la importancia de convivir mediante procesos de integración fundados en la reciprocidad, el reconocimiento y el respeto. Este reto implica tomar en cuenta el debate sobre la articulación entre hechos y normas, entre realidades sociales y principios filosóficos. Nuestra realidad social se caracteriza por la existencia innegable de la diversidad cultural y el hilo conductor de las reflexiones esbozadas en este trabajo es que la

${ }^{63}$ Alain-G. GAGNON, "Conjuguer communauté, autonomie et habilitation. La dure naissance d'une école de la diversité dans le monde occidental", en Michel SEYmour y Guy LAFOrest (eds.), Le fédéralisme multinational. Un modèle viable?, Peter Lang, Bruxelles, 2011, p. 103.

${ }^{64}$ Gagnon, La era de las incertidumbres, p. 153. 
coexistencia no debería fundamentarse en una política de la asimilación, la uniformidad y el confinamiento al ámbito privado de las convicciones culturales, porque esto implica cegarse ante las diferencias y, en consecuencia, ser ciego también ante el racismo, la discriminación y el reconocimiento de la pluralidad étnica y cultural. La coexistencia debe fundamentarse sobre la integración, la convivencia y la reciprocidad en la diferencia. Esto no necesariamente quiere decir que los ciudadanos deban ver sus identidades particulares reconocidas por el Estado, sino que los ciudadanos no estén dominados ni por los miembros de su comunidad, ni por la sociedad mayoritaria.

Algunos pensadores justifican los acomodos razonables sobre la base del reconocimiento de la igualdad en la diferencia; aquí se ha intentado ofrecer argumentos para justificar que es posible fundamentar estos acomodos sobre la apuesta por una libertad como no dominación que rehúsa la desigualdad en las relaciones de poder. Esta lectura solo puede darse en un republicanismo inclusivo que se aleje de la uniformidad, que permita la expresión pública de las diferencias en lugar de disimularlas y reprimirlas, que sea consciente de las posibilidades y de los efectos de la dominación que sobre las minorías puede ejercer la mayoría, y que apueste por una interpretación más flexible de ciertas normas considerando que el fin último es evitar situaciones de vulnerabilidad.

\section{REFERENCIAS BIBLIOGRÁFICAS}

Anctil, Pierre, “Quel accommodement raisonnable?": Éthique Publique, vol. 9, n. 1 (2007), pp. 186-191.

BoucharD, Gérard, “Qu'est-ce que 1'interculturalisme?": Revue de droit de McGill, n. 56 (2011), pp. 395-433.

—, L'Interculturalisme, Boréal, Montréal, 2012.

—, "What is Interculturalism?", en Alain-G. GAGnon y José María SAuca (eds.), Negotiating Diversity: Identity, Pluralism and Democracy, Peter Lang, Brussels, 2013.

BOUCHARD, Gérard, y TAYLOR, Charles, Accommodements et différences. Vers un terrain d'entente: la parole aux citoyens, Gouvernement du Québec, Québec, 2007.

-, Fonder l'avenir. Le temps de la conciliation, Gouvernement du Québec, Québec, 2008.

Bosset, Pierre, "Limites de l'accommodement: le droit a-t-il tout dit?": Éthique Publique, vol. 9, n. ${ }^{\circ} 1$ (2007).

Bosset, Pierre, y Foblets, Marie-Claire, “Le Québec et l'Europe face au besoin d'accommoder la diversité: disparité des concepts juridiques, convergence 
des résultats?", en Accommodements institutionnels et citoyens: cadres juridiques et politiques pour interagir dans des sociétés plurielles, Tendances de la cohésion sociale n. ${ }^{\circ}$ 21, Conseil de l'Europe, Bruxelles, 2009.

CARDINAL, Linda, y BRADY, Marie-Joie, "Ciudadanía y federalismo en Canadá: una relación difícil”, en Alain-G. GAGNON (dir.), El federalismo canadiense contemporáneo. Fundamentos, tradiciones e instituciones, Tirant lo Blanch y Generalitat de Catalunya, Valencia, 2010, p. 473.

Chaves, Pedro; Prieto, Carlos y Ramírez, René (eds.), Crisis del capitalismo neoliberal, poder constituyente y democracia real, Traficantes de sueños, Madrid, 2013.

Commission ontarienne des droits de la personne c. Simpson-Sears, Jugements de la Cour suprême du Canada, 2 R.C.S. 536, 1985.

Consejo De Europa, Libro Blanco sobre el Diálogo Intercultural: Vivir juntos con igual dignidad. Disponible en: http://www.coe.int/t/dg4/intercultural/Source/Pub_White_Paper/WhitePaper_ID_SpanishVersion.pdf (13-22014).

COURTOIS, Stéphane, "Le Québec face au pluralisme: un plaidoyer pour l'interculturalisme": Argument. Politique, société et histoire, vol. 13, n. ${ }^{\circ} 1$ (2010). Disponible en: http://www.revueargument.ca/article/2010-10-01/507-lequebec-face-au-pluralisme-un-plaidoyer-pour-linterculturalisme.html (136-2014).

De Francisco, Andrés, La mirada republicana, Catarata, Madrid, 2012.

De Sousa SAntos, Boaventura, "Las paradojas de nuestro tiempo y la plurinacionalidad", en Alberto Acosta y Esperanza Martínez (comps.), Plurinacionalidad. Democracia en la diversidad, Abya-Yala, Quito, 2009.

Del ÁGuila, Rafael, "Introducción al Monográfico especial sobre la teoría política contemporánea": Revista Española de Ciencia Política, n. 3 (2000).

Gagnon, Alain-G. (comp.), Quebec: Estado y Sociedad, Universidad de Guadalajara, Guadalajara (México), 2003.

-, Conjuguer communauté, autonomie et habilitation. La dure naissance d'une école de la diversité dans le monde occidental", en Michel Seymour y Guy LAFOREST (eds.), Le fédéralisme multinational. Un modèle viable?, Peter Lang, Bruxelles, 2011.

—, La era de las incertidumbres, Tirant lo Blanch, Valencia, 2013.

Gagnon, Alain-G. y SAUCA, José María (eds.), Negotiating Diversity: Identity, Pluralism and Democracy, Peter Lang, Brussels, 2013.

GorrotXategui AzURMENDi, Miren, "El interculturalismo quebequés en la encrucijada. De la crisis de los acomodamientos razonables a la Comisión Bouchard-Taylor": Revista de Estudios Políticos, n. ${ }^{\circ} 150$ (2010), pp. 175-223. 
Honohan, Iseult, Civic Republicanism, Routledge, London y New York, 2002. JAHANBEGLOO, Ramin, Elogio de la diversidad, Arcadia, Barcelona, 2007.

JeZEQUel, Myriam (dir.), Les accommodements raisonnables: quoi, comment, jusqu'où? Des outils pour tous, Éditions Yvon Blais, Québec, 2007.

KARMIS, Dimitris, "Pluralismo e identidad(es) nacional(es) en el Quebec contemporáneo: aclaraciones conceptuales, tipología y análisis del discurso", en Alain-G. GAGNON (comp.), Quebec: Estado y Sociedad, Universidad de Guadalajara, Guadalajara (México), 2003.

LACroIX, Justine, "Communautarisme et pluralisme dans le débat français. Essai d'élucidation": Éthique Publique, vol. 9, n. ${ }^{\circ} 1$ (2007).

Laborde, Cécile, Critical Republicanism. The Hijab Controversy and Political Philosophy, Oxford University Press, Oxford, 2008.

-, "Républicanisme critique vs. Républicanisme conservateur: repenser les 'accommodements raisonnables"': Critique Internationale, n. ${ }^{\circ} 44$ (2009), pp. 19-33.

—, Français, encore, un effort pour être républicains, Seuil, Paris, 2010.

LisÉE, Jean-François, Nous, Boréal, Montréal, 2007.

MÁız, Ramón, "Nacionalismo e inmigración en Francia: La republique une et indivisible y el affaire du foulard": Revista de Estudios Politicos (nueva época), n. ${ }^{\circ} 129$ (2005), pp. 5-37.

MACLURE, Jocelyn, "Un défense de multiculturalisme comme morale politique", en Myriam JÉZÉQuel (dir.), La justice à l'épreuve de la diversité culturelle, Éditions Yvon Blais, Montréal, 2007.

MCANDREw, Marie, "Pour un débat inclusif sur l'accommodement raisonnable": Éthique Publique, vol. 9, n. ${ }^{\circ} 1$ (2007).

OrTiz Leroux, Sergio, "Democracia liberal y democracia republicana: ¿ruptura o continuidad?": Isotimia. Revista Internacional de Teoría Politica y Juridica, n. ${ }^{\circ} 5$ (2011), pp. 55-72.

PALti, Elías, "Ideas políticas e historia intelectual: Texto y contexto en la obra reciente de Quentin Skinner": Prismas. Revista de historia intelectual, n. ${ }^{\circ} 3$ (1999), pp. 263-274.

PAReKh, Bhikhu, Rethinking Multiculturalism: Cultural Diversity and Political Theory, Palgrave Macmillan, Basingstoke, 2000.

Pettit, Philip, Republicanismo. Una teoría sobre la libertad y el gobierno, Paidós, Barcelona, 1999.

-, "De la República a la Democracia": Revista Internacional de Pensamiento Político, vol. 4 (2009), pp. 47-68.

RAMADAN, Tariq, "Accommodements pour les minorités ou accommodements pour tous et chacun. Réussir le 'vivre-ensemble' dans des sociétés plurielles", 
en Accommodements institutionnels et citoyens: cadres juridiques et politiques pour interagir dans des sociétés plurielles, Tendances de la cohésion sociale n. ${ }^{\circ} 21$, Conseil de l'Europe, Bruxelles, 2009.

Renaut, Alain, “ $¿ Q u$ 'est-ce qu'une philosophie politique juste? Essai de philosophie politique appliquée": Politique et Sociétés, vol. 22, n. 3 (2003), pp. 155-178.

Rosanvallon, Pierre, Le sacre du citoyen, Gallimard, Paris, 1992.

Ruiz VieYTEZ, Eduardo, "Las prácticas de armonización como instrumento de gestión pública de la diversidad religiosa": Documentos del Observatorio del pluralismo religioso en España, n. ${ }^{\circ} 4$ (2012).

Sentencia Thlimmenos contra Grecia, Tribunal Europeo de Derechos Humanos de 6 de abril de 2000.

Tully, James, "Introduction", en Multinational Democracies, Cambridge University Press, Cambridge, 2001.

-, "La conception républicaine de la citoyenneté dans les sociétés multiculturelles et multinationales": Politiques et Sociétés, vol. 1, n. 20 (2001), pp. 123-146.

Velasco, Juan Carlos, "La noción republicana de ciudadanía y la diversidad cultural": Isegoría, n. 33 (2005), pp. 191-206.

WiEviorka, Michel, La Diversité. Rapport à la ministre de l'Enseignement supérieur et de la Recherche, Robert Laffont, Paris, 2008.

WoEHRLing, José, "La libertad de religión, el derecho al acomodamiento razonable y la obligación de neutralidad religiosa del Estado en el derecho canadiense": Revista catalana de dret públic, n. ${ }^{\circ} 33$ (2006), pp. 1-32.

—,"Neutralité de 1'État et accommodements: convergence ou divergence?": Options Politiques (Septembre 2007). 